\title{
Ameliorative effects of ark clams (Scapharca subcrenata and Tegillarca granosa) on endothelial dysfunction induced by a high-fat diet
}

\author{
Saoraya Chanmuang ${ }^{1}$, Orawan Meemalai ${ }^{1}$, Kitipong Promyo ${ }^{2}$, Kyung-Hee Park' ${ }^{1}$ Suthipong Pongworn ${ }^{3}$,
} Dal-Seong Gong ${ }^{4}$, Min-Ho Oak ${ }^{4}$, Jeong-Yong Cho ${ }^{5}$, Seong-Gook Kang ${ }^{1}$ and Kyung-Sik Ham ${ }^{1 *}$ (1)

\begin{abstract}
Endothelial dysfunction is directly involved in consequence of various metabolic syndromes such as diabetes and hypertension. In this study, we investigated the preventive effects of two ark clams [ark shell (AS, Scapharca subcrenata) and granular ark (GA, Tegillarca granosa)] on endothelial dysfunction induced by a high-fat diet. Wistar rats were divided into four groups as follows: control (normal diet), HF (high-fat diet), AS (high-fat diet + 5\% AS powder), and GA (high-fat diet + 5\% GA powder) for 12 weeks. AS and GA diets enhanced vascular reactivity of the rat thoracic aorta and significantly increased expression levels of vascular relaxation-related proteins (p-Akt-ser473 and p-eNOSser1177). Ark clam supplement reduced endothelin-1 expression level, as compared to the HF group. Additionally, AS and GA showed a trend of improving insulin sensitivity compared to HF. Our results suggest that AS and GA enhance vascular reactivity and ameliorated endothelial dysfunction induced by a high-fat diet.
\end{abstract}

Keywords: Ark clam, Endothelial dysfunction, High-fat diet, Scapharca subcrenata, Tegillarca granosa

\section{Introduction}

Vascular homeostasis is maintained by the endothelial cells through manifold complex interactions with cells in the vessel wall. Endothelium normalizes vascular tone by balancing vasodilators and vasoconstrictors [1]. Failure of endothelial function is associated with a variety of metabolic syndrome including cardiovascular diseases [2], insulin resistance [3], and hypertension [4]. Nitric oxide (NO), the key regulator of the vasodilatory process, is generated from L-arginine through the catalyzation of endothelial NO synthase [2]. Endothelial dysfunction reduces vascular NO productivity, resulting in various vascular diseases. Interestingly, there is evidence

\footnotetext{
*Correspondence: ksham@mokpo.ac.kr

${ }^{1}$ Department of Food Engineering and Solar Salt Research Center, Mokpo

National University, Muan, Jeonnam 58554, Republic of Korea

Full list of author information is available at the end of the article
}

suggesting that the foods can alter endothelial function negatively or positively [5]. Supplements of some foods and nutrients improve an endothelial function [5, 6].

Ark clams, including ark shell (AS, Scapharca subcrenata) and granular ark (GA, Tegillarca granosa), are edible marine bivalve mollusks. AS and GA are widely consumed as foods in China and Korea. Ark clams are rich in free amino acids such as taurine, glycine, arginine, etc.[7]. Several free amino acids are recognized as useful nutrients for improving endothelial function [8-11]. In particular, taurine that is highly contained in ark clams was reported to have endothelial protective activity [8] and improved vascular function [9]. In addition, several antioxidative and/or anticancer peptides have been isolated and identified from protein hydrolysates of GA muscle [12, 13]. We hypothesized that ark clams could help to prevent endothelial dysfunction. However, the 
preventive effects of ark clams on endothelial dysfunction in an animal model has not yet been assessed.

The chronic high-fat (HF) diet induces endothelial dysfunction and insulin resistance leads to cardiovascular diseases and diabetes [14, 15]. The HF diet has been widely used for assessing the preventive effect of foods on endothelial dysfunction and insulin resistance [16, 17]. In this study, the ameliorative effects of AS and GA on HFinduced endothelial dysfunction were evaluated.

\section{Materials and methods}

\section{Materials and chemicals}

$\mathrm{AS}$ and $\mathrm{BC}$ were purchased from the local market located in Boseong County, Korea. The ark clams were steamed for $3 \mathrm{~min}$ and the muscles obtained after shucking were dried by hot air dryer at $50{ }^{\circ} \mathrm{C}$ for 4 days. The dried muscles were ground by a grinder and stored at $-20^{\circ} \mathrm{C}$ until used.

Horseradish peroxidase (HRP)-conjugated goat antirabbit immunoglobin was procured from Millipore Co. (Billerica, MA, USA). The antibodies of phosphorylated Akt-Sers73 (p-Akt-Ser473) and endothelin-1 (ET-1) were obtained from Santa Cruz Biotechnology (Santa Cruz, CA, USA). The antibodies for eNOS and phosphorylatedeNOS-Ser1177 (p-eNOS-Ser1177) were procured from Cell Signaling (Danvers, MA, USA). Reagent salt, acetylcholine chloride (Ach), sodium nitroprusside dehydrate (SNP), and phenylephrine hydrochloride was purchased from Sigma-Aldrich Chemical Co. (St. Louis, MO, USA). Antibodies of insulin receptor substrate-1 (IRS1), phosphorylated IRS1 Serine307 (pIRS1ser307), and glucose transporter 4 (GLUT4) were procured from Upstate Biotech, Inc. (Lake Placid, NY, USA). Rabbit anti-GAPDH polyclonal antibody was obtained from Ab Frontier (Seoul, Korea). All other chemical reagents and solvents used in this study were of analytical grade.

\section{Free amino acid analysis}

The free amino acid content in the dried ark clam powders was determined by a Sykam S430 amino acid analyzer (GmbH, Eresing, Germany) [18].

\section{Animal studies}

Male Wistar rats (6 weeks old) were purchased from Damool Science (Daejeon, Korea). The rats were housed at room temperature $\left(25 \pm 1{ }^{\circ} \mathrm{C}\right)$, humidity $(55 \pm 5 \%)$, and light cycle (12 h; 6:00 to 18:00) and given ad libitum access to food and water. All rats were adapted for 1 week, randomly divided into 4 groups $(n=8)$, and treated with a special diet for 12 weeks as follows: Control (normal diet), HF (HF diet, 40\% lard), AS (HF diet $+5 \%$ AS), and GA (HF diet $+5 \%$ GA). The animal experiment protocol was approved by the Committee on Animal Care and Use of Mokpo National University (MNU-IACUC-2015-032).

\section{Assessment of vascular reactivity}

The thoracic aorta ring was mounted in standard organ baths containing $10 \mathrm{~mL}$ of physiological salt solution and maintained at $\mathrm{pH} 7.4$, temperature $37^{\circ} \mathrm{C}$, and continuously bubbled with $95 \% \mathrm{O}_{2}$ and $5 \% \mathrm{CO}_{2}$. The samples were constricted followed by re-equilibration two times using a high-potassium Krebs solution ( $80 \mathrm{mM} \mathrm{KCl}$ ), then contracted to $1 \mu \mathrm{M}$ phenylephrine and exposed to Ach $\left(10^{-9}\right.$ to $\left.3 \times 10^{-5} \mathrm{M}\right)$ and SNP $\left(10^{-10}\right.$ to $\left.3 \times 10^{-5} \mathrm{M}\right)$. Changes in tension were recorded by using a force-displacement transducer (HugoSachs, Germany).

\section{Western blotting}

Protein of thoracic aorta and adipose tissue samples were extracted and determined by the Bradford assay [19]. The protein samples were separated on $10 \%$ polyacrylamide gel by SDS-PAGE and transferred to PVDF membranes. After treating with blocking buffer for $1 \mathrm{~h}$, the membrane was reacted overnight with primary antibodies at room temperature. Follow by incubation with secondary antibodies for $1 \mathrm{~h}$ and bands were visualized by the chemiluminescence reagent. The bands and their intensities were photographed and analyzed by ImageJ $1.50 \mathrm{i}$ software (MD, USA).

\section{Immunohistological study}

Samples were fixed in Bouin's solution for $24 \mathrm{~h}$, dehydrated in graded alcohol, and embedded in paraffin. Blocks were cut into $4 \mu \mathrm{m}$ sections, deparaffined in xylene, and rehydrated in series of alcohol and distilled water. The slides were incubated for $10 \mathrm{~min}$ in the antigen retrieval solution (microwave oven), blocked with $3 \% \mathrm{H}_{2} \mathrm{O}_{2}$ solution for $5 \mathrm{~min}$, incubated with $10 \%$ normal goat serum for $30 \mathrm{~min}$, and incubated with primary antibody (1:200) overnight at room temperature. The slides were incubated with the biotinylated secondary antibody (1:200) for $2.5 \mathrm{~h}$ at room temperature and followed by incubation with avidin-biotin-peroxidase for $30 \mathrm{~min}$. The colors were developed by $0.1 \%$ DAB chromogen solution and the photographs were taken by microscopes (Olympus, BX43).

\section{Statistical analysis}

The data were expressed as a means \pm S.E.M. using SPSS v12.0 (Chicago IL, USA). The statistical significance of mean was determined by ANOVA following the posthoc Tukey's test. The $P$ value of $<0.05$ was considered significant. 


\section{Results and discussion}

\section{Free amino acid content}

The contents of taurine and free amino acids in the AS and GA powders are shown in Table 1 . The AS powder showed higher total free amino acid content than the GA powder. Taurine was the most predominant in both AS and GA. The taurine content in the AS powder was higher than that in the GA powder. Additionally, free amino acids, including glutamic acid, glycine, arginine, alanine, $\beta$-alanine, and aspartic acid, were abundant in the dried AS and GA powders. Glutamic acid, glycine, and arginine in the AS powder and aspartic acid in the GA powder were more abundant. Ark clams have been found to be rich in taurine, a non-essential amino acid that has been reported to have various health-beneficial effects, including improvement of vascular endothelial

Table 1 Free amino acid content of cockle powder and raw egg yolk

\begin{tabular}{|c|c|c|c|}
\hline Component & $\begin{array}{l}\text { Ark shell } \\
\text { (AS) } \\
(\mathrm{mg} / 100 \mathrm{~g})\end{array}$ & $\begin{array}{l}\text { Granular } \\
\text { ark (GA) } \\
(\mathrm{mg} / 100 \mathrm{~g})\end{array}$ & $\begin{array}{l}\text { Raw egg yolk } \\
(\mathrm{mg} / 100 \mathrm{~g})\end{array}$ \\
\hline Taurine & 1339 & 811 & \\
\hline Glutamic acid & 366 & 258 & 117 \\
\hline Glycine & 314 & 55 & 25 \\
\hline Arginine & 307 & 102 & 158 \\
\hline Alanine & 276 & 251 & 63 \\
\hline Aspartic acid & 198 & 387 & 50 \\
\hline$\beta$-Alanine & 141 & 115 & \\
\hline Lysine & 33 & 24 & 87 \\
\hline Leucine & 28 & 13 & 74 \\
\hline Valine & 22 & 14 & 66 \\
\hline Tyrosine & 22 & 10 & 69 \\
\hline Isoleucine & 17 & 8 & 39 \\
\hline Phenylalanine & 16 & 5 & 34 \\
\hline Threonine & 15 & 21 & 47 \\
\hline Serine & 15 & 11 & 60 \\
\hline Histidine & 12 & 6 & 15 \\
\hline Methionine & 8 & 3 & 16 \\
\hline$\gamma$-Amino-n-butyric acid & 2 & 3 & \\
\hline Total & 3265 & 2138 & 976 \\
\hline
\end{tabular}

a Data collected from the report by Nimalaratne et al. Food Chemistry 129 : 155-161 (2011) function and hypertension [8, 9]. Moreover, glycine and arginine also enhance endothelial function by increasing nitric oxide bioavailability $[10,11]$. Therefore, taurine might be one of the key factors that contribute to the preventive effects of AS and GA on vascular endothelial dysfunction.

\section{AS improved vascular reactivity}

Previous studies have reported that HF causes obesity and leads to endothelial dysfunction [14]. To investigate the potential effects of AS on endothelial dysfunction, arterial segments were collected, and vascular reactivity was determined. As shown in Fig. 1a, the HF group showed a significant decrease in endothelium-dependent relaxation induced by Ach, as compared to the control group. Consistent with our results, previous studies have reported that HF impairs vasorelaxation response to Ach in the rat aorta [14]. The AS supplement significantly increased endothelium-dependent relaxation in the HF diet-fed rat. The half-maximal response concentration (EC50 value) of Ach in the control, HF, and AS groups were $10.9 \pm 5.0,18.0 \pm 3.1$, and $13.5 \pm 1.7 \mathrm{nM}$, respectively. In addition, the maximal vasorelaxant effect of Ach in the control, HF, and AS groups were $91.7 \pm 1.0$, $76.4 \pm 2.2$, and $84.0 \pm 1.4 \%$, respectively. All groups also exhibited dose-dependent relaxation induced by SNP, the $\mathrm{NO}$ donor. However, there was no significant difference in EC50 value and the maximal vasorelaxant effect of SNP among all groups, indicating that there was no significant difference in endothelial-independent relaxation. The EC50 value of SNP in the control, HF, and AS groups were $6.8 \pm 1.1,8.0 \pm 1.2$, and $6.4 \pm 1.2 \mathrm{nM}$, respectively. The maximal vasorelaxant effect of SNP in the control, HF, and AS groups were $98.4 \pm 1.0,98.0 \pm 1.3$, and $98.16 \pm 0.7$, respectively. These results suggest that AS improves vascular reactivity by ameliorating HF-induced endothelial dysfunction.

\section{Ameliorative effects of AS and GA on endothelial dysfunction}

Acetylcholine induces vascular relaxation by activating the calmodulin-binding domain of eNOS to produce NO [20]. The reduction of NO is the main characteristic of endothelial dysfunction [21]. Thus, the expression of NOgenerated proteins were evaluated. As expected, the HF

(See figure on next page.)

Fig. 1 Concentration-response curves of Ach-induced endothelium-dependent relaxation a and SNP-induced endothelium-independent relaxation $\mathbf{b}$ in the phenylephrine-contracted thoracic aorta of the control, HF, and AS groups. The western blot analysis of endothelial dysfunction-related proteins in thoracic aorta tissue and its relative intensities, p-Akt ser473 (c), p-eNOS-Ser1177 (d), and p-eNOS Thr495 (e). Immunohistochemistry staining of ET-1 in the thoracic aorta sample using antibody against ET-1 and visualized with peroxidase displaying different staining intensity (brown color) ( $\mathrm{f}$ ) and their immune positivity expressed as area \% (g). Data are expressed as mean \pm SEM ( $\mathrm{n}=8$ ). ${ }^{\#} P<0.05 \mathrm{vs.}$ Control, ${ }^{*} P<0.05$ vs. HF 

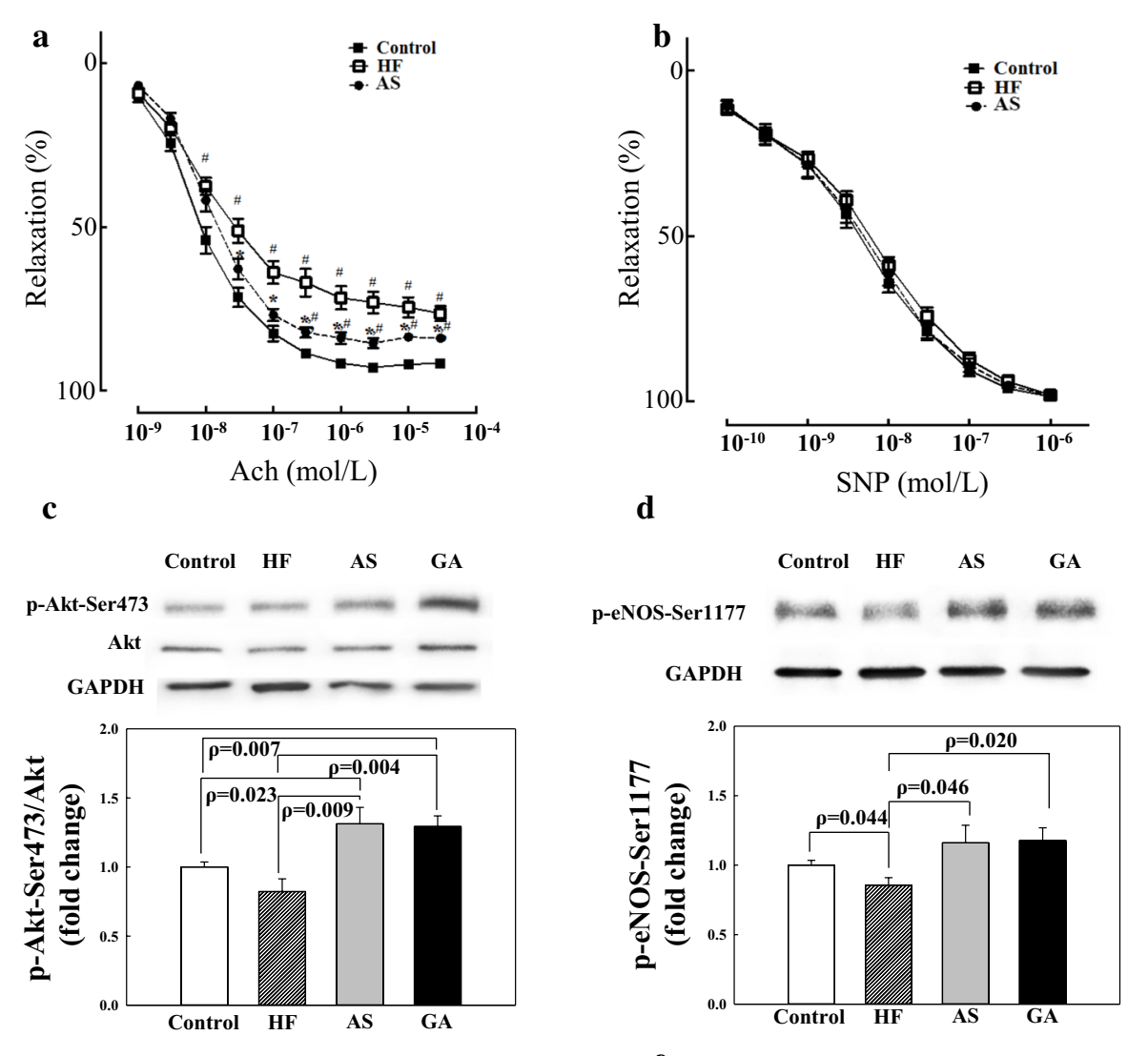

e

f
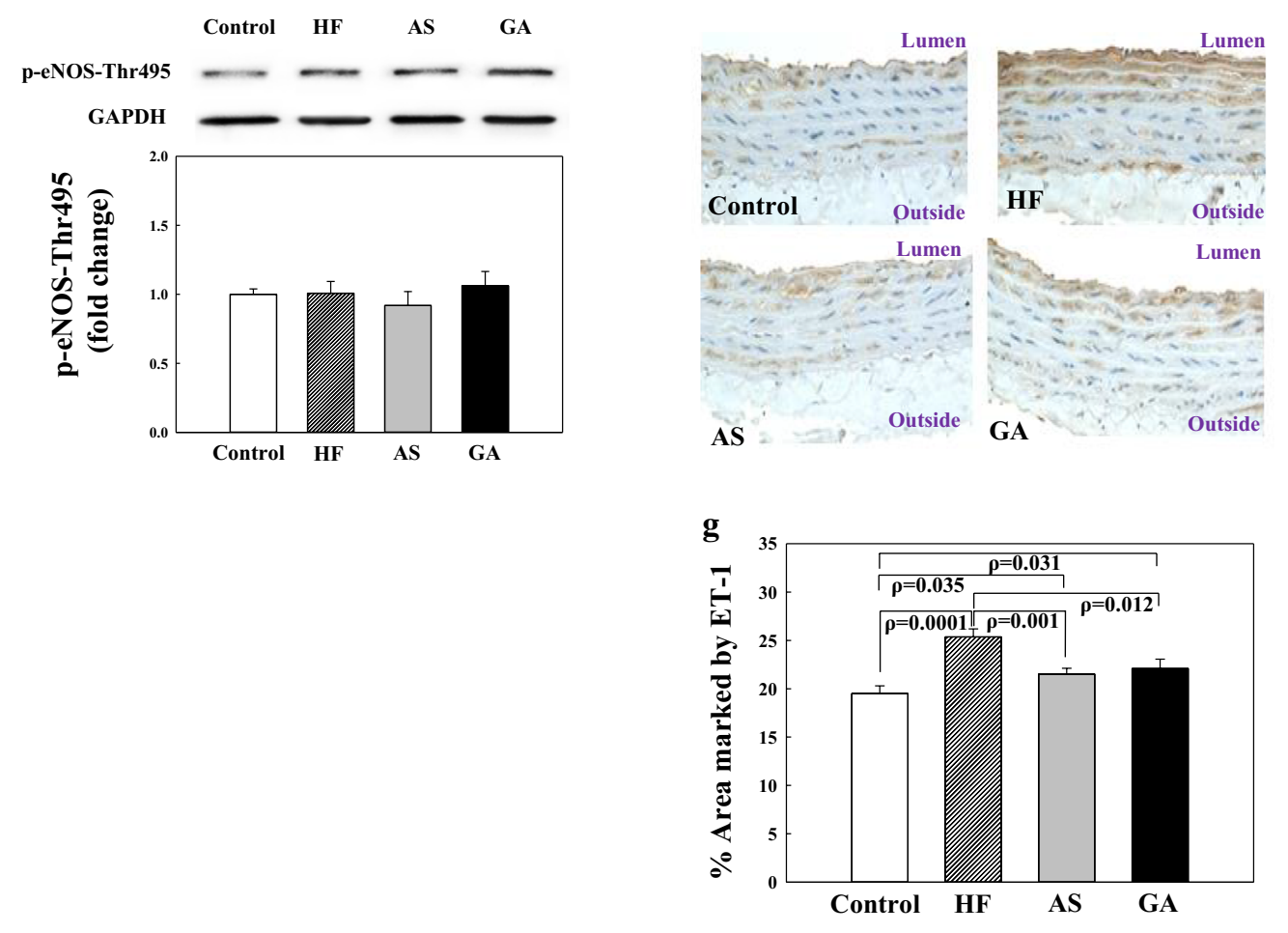
diet reduced the expression of p-Akt ser473 and p-eNOSSer1177 compared to the control (Fig. 1c, d). The AS and GA supplement increased expression levels of p-Akt ser473 and p-eNOS-Ser1177 in the HF-fed rat (Fig. 1c, d) and expressions of those proteins were even higher than expressions of those proteins in control. However, the different expression levels of p-eNOS Thr495 among the groups were not observed (Fig. 1e). Previous studies reported that the NO production is upregulated by the eNOS activity via modulation of p-eNOS-Ser1177 and p-Akt ser473 [22, 23], whereas p-eNOS-Thr495 is a negative regulator and associated with a decreased enzyme activity [24]. The rise in the expression level of p-eNOSSer1177 in AS and GA diet resulted in the amplified enzymatic activity of eNOS which was led to increased
NO content in vascular endothelial cells. Our results suggest, at least in part, that AS and GA increase vascular reactivity by improving endothelial dysfunction through enhancing Akt-induced eNOS phosphorylation at its active site. ET-1 is a strong vasoconstrictor produced in vascular endothelial cells. Failure of the physiological balance between NO and ET-1 causes endothelial dysfunction [22, 25]. Interestingly, immunohistochemistry staining of ET-1 brown spots in the thoracic aorta (Fig. 1f) and their percentage of the area (Fig. 1g) showed that AS and GA groups have significantly diminished ET-1 expression levels compared to the HF group. As the physiological balance between NO and ET-1 is considered important in endothelial function, AS and GA may ameliorate endothelial dysfunction by decreasing

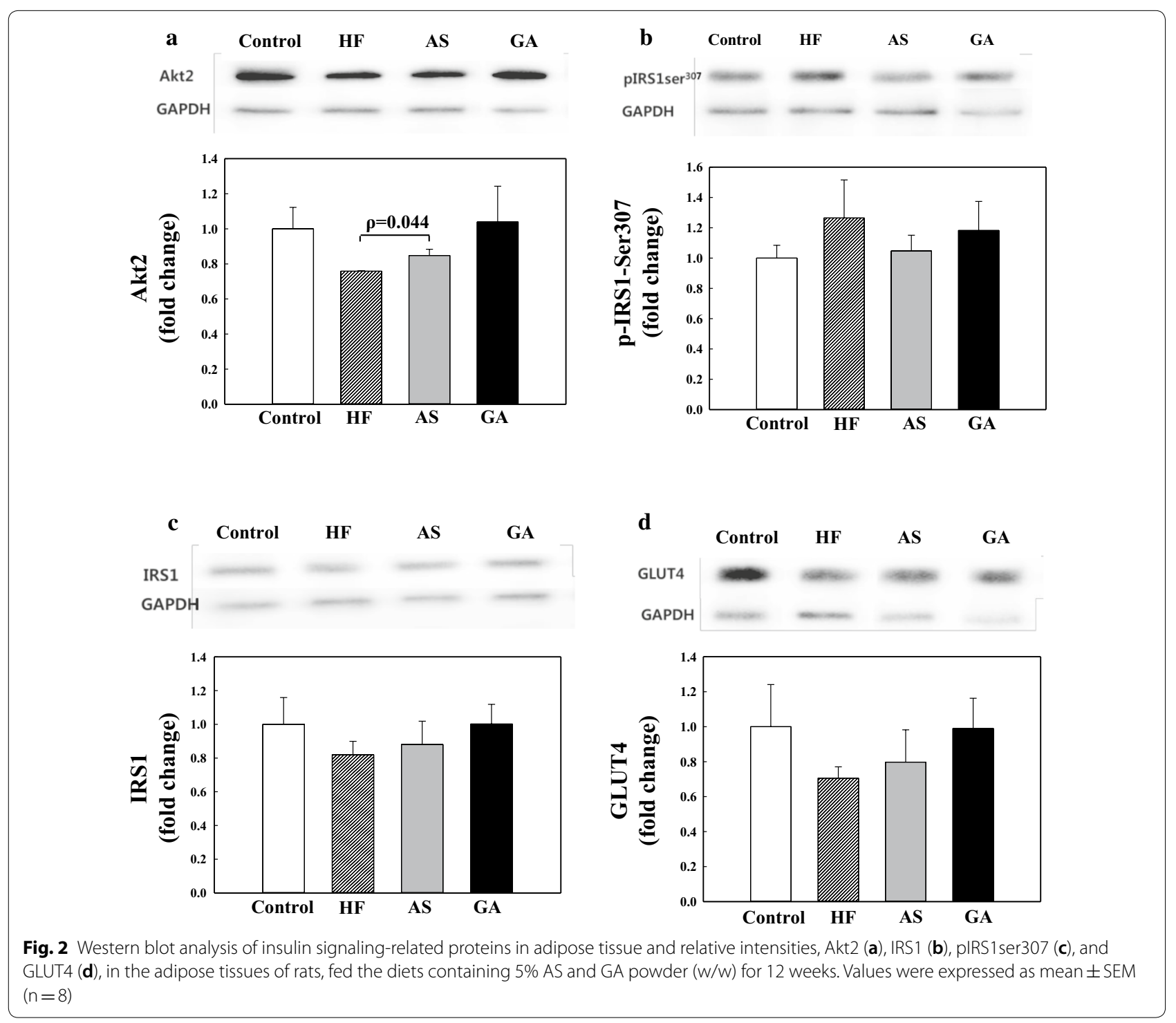


ET-1 and improving phosphorylation of NO-production-related proteins, and may lead to increased vascular relaxation.

\section{Effects of AS and GA on insulin sensitivity}

Endothelial dysfunction has been reported to be associated with insulin resistance in diabetes [26]. Insulin binding to its specific receptor stimulates the phosphorylation of IRS and activates the IRS/PI3K pathway that regulates glucose uptake in metabolic tissues and controls NO release from endothelial cells [26]. Phosphorylation of IRS proteins on tyrosine residues activates insulin signaling and stimulates the translocation of GLUT4. On the other hand, serine phosphorylation of IRS proteins causes insulin resistance [27]. The HF diet showed lower expression levels of IRS1, Akt2, and GLUT4 and higher expression levels of pIRS1ser307, as compared to the control (Fig. 2). Similar to our results, it was demonstrated that HF induced insulin resistance by impairing insulin signaling [28]. AS and GA showed a trend of improving insulin signaling by increasing of IRS1 and GLUT4 expression (Fig. 2b, d) and by decreasing pIRS1ser307 expression (Fig. 2c). However, significant differences were not observed. The protein expression level of Akt2, a signaling protein in the IRS/PI3K pathway [29], was significantly increased in the AS group compared to the HF group (Fig. 2a).

Here we found that AS and GA enhance vascular activities and ameliorate endothelial dysfunction by increasing the expression levels of vascular relaxation-related proteins and suppressing ET-1 protein expression. Moreover, AS and GA appeared to have the potential to improve insulin sensitivity. Protein hydrolysates of AS and GA have been reported to have in vitro anti-angiogenic, antioxidant, and acetylcholinesterase inhibitory activities [30-32]. Taurine was known to have endothelial protective activity and improve vascular function by the restoration of redox homeostasis [8]. Additionally, glycine and L-arginine have the ability to prevented endothelial dysfunction [10, 11]. In addition to free amino acids including taurine, other components in the clams such as minerals and betaine may contribute to the prevention effects of AS and GA on endothelial dysfunction $[33,34]$. Betaines are known to convert homocysteine, which is reported to have adverse effects by disturbing endothelial function, to methionine as a methyl donor [35]. It was reported that both ark clams contain a high amount of betaines [34]. Even though the mechanisms to prevent endothelial function by AS and GA are not clear, our study provides evidence that AS and GA increase vascular reactivity and improved HF-induced endothelial dysfunction.

\section{Acknowledgements}

Not applicable

Authors' contributions

$\mathrm{KSH}, \mathrm{MHO}, \mathrm{SC}$, and $\mathrm{KP}$ designed experiment. SC, KP, OM, and KHP performed and analyzed data from endothelial dysfunction- and insulin resistance-related proteins. SP performed and analyzed data from immunohistological work. DSG performed measurement of vascular reactivity. KSH, SGK and MHO supervised research. SC, JYC, and KSH prepared the manuscript, with contributions from all authors. All authors read and approved the final manuscript.

\section{Funding}

This study was supported by a Regional Infrastructure Specialized Support Project from the Ministry of SMEs and Startups (MSS) of Korea Government. The project was supposed to help Fishery Company Beolgyo Cockle.

\section{Availability of data and materials}

The datasets used and analyzed in this study are available from the corresponding author upon reasonable request.

\section{Competing interests}

The authors declare that they have no competing interests.

\section{Author details}

${ }^{1}$ Department of Food Engineering and Solar Salt Research Center, Mokpo National University, Muan, Jeonnam 58554, Republic of Korea. ${ }^{2}$ School of Food Technology, Institute of Agricultural Technology, Suranaree University of Technology, Nakhon Ratchasima 30000, Thailand. ${ }^{3}$ Department of Agro-Industrial, Food and Environmental Technology, Applied Science Faculty, King Mongkut's University of Technology North, Bangkok 10800, Thailand. ${ }^{4}$ College of Pharmacy, Mokpo National University, Muan, Jeonnam 58554, Republic of Korea. ${ }^{5}$ Department of Food Science and Technology, Chonnam National University, Gwangju 61186, Republic of Korea.

Received: 14 July 2020 Accepted: 20 October 2020

Published online: 07 November 2020

\section{References}

1. Widlansky ME, Gokce N, Keaney JF, Vita JA (2003) The clinical implications of endothelial dysfunction. J Am Coll Cardiol 42:1149-1160

2. Lee SK, Khambhati J, Bhargava A, Engels MC, Sandesara PB, Quyyumi AA (2017) Endothelial dysfunction and metabolic syndrome. Hypertens J 3:72-80

3. Ormazabal V, Nair S, Elfeky O, Aguayo C, Salomon C, Zuñiga FA (2018) Association between insulin resistance and the development of cardiovascular disease. Cardiovasc Diabetol 17:122

4. Konukoglu D, Uzun H (2016) Endothelial dysfunction and hypertension. Adv Exp Med Biol 956:511-540

5. Sijtsma FP, Meyer KA, Steffen LM, Van Horn L, Shikany JM, Odegaard AO, Gross MD, Kromhout D, Jacobs DR Jr (2014) Diet quality and markers of endothelial function: the CARDIA study. Nutr Metab Cardiovasc Dis 24:632-638

6. Cuevas AM, Germain AM (2004) Diet and endothelial function. Biol Res 37:225-230

7. Kim KS, Lim JJ, Bae TJ, Park CK, Kim MH (2002) Characteristic of food components in granular ark and ark shell. J Korean Fish Soc 35:512-518

8. Khadieva TA, Pokrovskaya TG, Belousova YV (2019) Pharmacological correction of endothelial dysfunction using ademethionin and taurine. Res Results Pharmacol 5:13-21

9. Katakawa M, Fukuda N, Tsunemi A, Mori M, Maruyama T, Matsumoto T, Abe M, Yamori Y (2016) Taurine and magnesium supplementation enhances the function of endothelial progenitor cells through antioxidation in healthy men and spontaneously hypertensive rats. Hypertens Res 39:848-856

10. Gómez-Zamudio JH, García-Macedo R, Lázaro-Suárez M, Ibarra-Barajas M, Kumate J, Cruz M (2015) Vascular endothelial function is improved by oral glycine treatment in aged rats. Can J Physiol Pharmacol 93:465-473

11. Kamada $Y$, Nagaretani $H$, Tamura $S$, Ohama T, Maruyama T, Hiraoka H, Yamashita S, Yamada A, Kiso S, Inui Y, Ito N, Kayanoki Y, Kawata S, 
Matsuzawa Y (2001) Vascular endothelial dysfunction resulting from $\mathrm{L}$-arginine deficiency in a patient with lysinuric protein intolerance. J Clin Invest 108:717-724

12. Chi CF, Hu FY, Wang B, Tao Li, Ding GF (2015) Antioxidant and anticancer peptides from the protein hydrolysate of blood clam (Tegillarca granosa) muscle. J Funct Foods 15:301-313

13. Yang XR, Qiu YT, Zhao YQ, Chi CF, Wang B (2019) Purification and characterization of antioxidant peptides derived from protein hydrolysate of the marine bivalve mollusk Tergillarca granosa. Mar Drugs 17:251

14. Oishi JC, Castro CA, Silva KA, Fabricio V, Cárnio EC, Phillips SA, Duarte ACGO, Rodrigues GJ (2018) Endothelial dysfunction and inflammation precedes elevations in blood pressure induced by a high-fat diet. Arq Bras Cardiol 110:558-567

15. Collino M, Mastrocola R, Nigro D, Chiazza F, Aragno M, D’Antona G, Minetto MA (2014) Variability in myosteatosis and insulin resistance induced by high-fat diet in mouse skeletal muscles. Biomed Res Int 2014:569623

16. Song W, Wang Z, Zhang X, Li Y (2018) Ethanol extract from Ulva prolifera prevents high-fat diet-induced insulin resistance, oxidative stress, and inflammation response in mice. Biomed Res Int 2018:1374565

17. Furuuchi R, Shimizu I, Yoshida Y, Hayashi Y, Ikegami R, Suda M, Katsuumi G, Wakasugi T, Nakao M, Minamino T (2018) Boysenberry polyphenol inhibits endothelial dysfunction and improves vascular health. PLOS ONE 13:e0202051

18. Kim RH, Asaduzzaman AKM, You CH, Chun BS (2013) Stability of Antioxidant Properties and essential amino acids in squid viscera hydrolysate produced using subcritical water. Fish Aquat Sci 16:71-78

19. Bradford MM (1976) A rapid and sensitive method for the quantitation of microgram quantities of protein utilizing the principle of protein-dye binding. Anal Biochem 72:248-254

20. Zhao Y, Vanhoutte PM, Leung SW (2015) Vascular nitric oxide: beyond eNOS. J Pharmacol Sci 129:83-94

21. Endemann DH, Schiffrin EL (2004) Endothelial dysfunction. J Am Soc Nephrol 15:1983-1992

22. Yuyun MF, Ng LL, Ng GA (2018) Endothelial dysfunction, endothelial nitric oxide bioavailability, tetrahydrobiopterin, and 5-methyltetrahydrofolate in cardiovascular disease. Where are we with therapy? Microvasc Res 119:7-12

23. Dimmeler S, Fleming I, Fisslthaler B, Hermann C, Busse R, Zeiher AM (1999) Activation of nitric oxide synthase in endothelial cells by Aktdependent phosphorylation. Nature 399:601-605
24. Förstermann U, Sessa WC (2012) Nitric oxide synthases: regulation and function. Eur Heart J 33:829-837

25. Sánchez A, Martínez P, Muñoz M, Benedito S, García-Sacristán A, Hernández M, Prieto D (2014) Endothelin-1 contributes to endothelial dysfunction and enhanced vasoconstriction through augmented superoxide production in penile arteries from insulin-resistant obese rats: role of ET(A) and ET(B) receptors. Br J Pharmacol 171:5682-5695

26. Del Turco S, Gaggini M, Daniele G, Basta G, Folli F, Sicari R, Gastaldelli A (2013) Insulin resistance and endothelial dysfunction: A mutual relationship in cardiometabolic risk. Curr Pharm Des 19:2420-2431

27. Kim B, Feldman EL (2012) Insulin resistance in the nervous system. Trends Endocrinol Metab 23:133-141

28. Liu Z, Patil IY, Jiang T, Sancheti H, Walsh JP, Stiles BL, Yin F, Cadenas E (2015) High-fat diet induces hepatic insulin resistance and impairment of synaptic plasticity. PLoS ONE 10:e0128274

29. Huang X, Liu G, Guo J, Su Z (2018) The PI3K/AKT pathway in obesity and type 2 diabetes. Int J Biol Sci 14:1483-1496

30. Lim CW, Park HY, Shim KB, Yoon NY, Kim YK (2012) Anti-angiogenesis activity and characterization of extract of ark shell Scapharca subcrenata. Kor J Fish Aquat Sci 45:303-306

31. Hyung JH, Ahn CB, Je JY (2017) Ark shell protein hydrolysates inhibit adipogenesis in mouse mesenchymal stem cells through the downregulation of transcriptional factors. RSC Adv 7:6223

32. Kim JB, Kim JM, Lee YM, Baek IS, Lee SC (2014) Antioxidant activity and acetylcholinesterase inhibitory activity of ark shell (Scapharca broughtonii). Korean J Food Cook Sci 30:212-218

33. Nguyen TT, Choi YJ, Rohmah Z, Jeong SB, Hwang DJ, Jung YG, Cho BD (2017) Seasonal variations of nutritional components in cockles (Tegillarca granosa) processed from the Southern Coast of Korea. Cogent Food Agric 3:1360102

34. Park CK (2002) Comparison of extractive nitrogenous constituents in the Three Species of raw bloody clams, Scaphrca broughtonii, S. subcrenata, and Tegillarca granosa Extracts. Korean J Food Sci Technol 34:954-961

35. Esse R, Barroso M, Tavares de Almeida I, Castro R (2019) The contribution of homocysteine metabolism disruption to endothelial dysfunction: State-of-the-Art. Int J Mol Sci 20:867

\section{Publisher's Note}

Springer Nature remains neutral with regard to jurisdictional claims in published maps and institutional affiliations.

\section{Submit your manuscript to a SpringerOpen ${ }^{\circ}$ journal and benefit from:}

- Convenient online submission

- Rigorous peer review

- Open access: articles freely available online

- High visibility within the field

Retaining the copyright to your article

Submit your next manuscript at springeropen.com 